American Journal of Infectious Diseases 3 (1): 1-6, 2007

ISSN 1553-6203

(C) 2007 Science Publications

\title{
Successful Treatment of Both Mother and Infant in Pregnancy-Associated Group A Streptococcal Toxic Shock Syndrome
}

\author{
${ }^{1}$ Takayuki Tanaka, ${ }^{1}$ Kousaku Matsubara, ${ }^{2}$ Yumiko Umemoto, ${ }^{3}$ Hideto Harada, \\ ${ }^{4}$ Atsushi Ohyama, ${ }^{5}$ Miyoko Endo and ${ }^{6}$ Chihiro Katsukawa \\ Departments of ${ }^{1}$ Pediatrics, ${ }^{2}$ Obstetrics and Gynecology, ${ }^{3}$ Orthopedics, ${ }^{4}$ Division of Nephrology, \\ Department of Internal Medicine, Nishi-Kobe Medical Center, \\ 5-7-1 Kojidai, Nishi-ku, Kobe 651-2273, Japan \\ ${ }^{5}$ Department of Microbiology, Tokyo Metropolitan Institute of Public Health, \\ 3-24-1 Hyakunin-cho, Shinjuku-ku, Tokyo 160-0073, Japan \\ ${ }^{6}$ Department of Microbiology, Osaka Prefectural Institute of Public Health, \\ 1-3-69 Nakamichi, Higashinari-ku, Osaka, 537-0025, Japan
}

\begin{abstract}
All perinatal cases of group A streptococcal toxic shock syndrome (STSS) previously documented in English literature have been fatal for the mother, the fetus or both. We present the first report of successful treatment of a mother-infant pair with perinatal STSS. A pregnant woman developed STSS at 34 weeks' gestation $3 \mathrm{~h}$ after delivery, following a 25-h history of fever and sore throat. The patient received intravenous penicillin, clindamycin and immnoglobulins and continuous hemodialysis, along with numerous supportive agents during early clinical course. The newborn infant was born with mild asphyxia and developed transient tachypnea. Both mother and infant survived without any sequelae. Streptococcus pyogenes was isolated from the patient's blood, nasopharynx of the infant and throat of two family members. These strains were identically type T1M1 (emml) and produced streptococcal pyrogenic exotoxins A (SPEA) and B. SPEA was remarkably elevated in the maternal blood, but not in the infant's blood. Extremely low serum anti-SPEA antibody levels might have predisposed the mother to severe invasive infection. This case highlights the importance of early recognition, prompt and intensive multimodal therapy and rapid delivery before a transfer of pathogen and its toxin to the fetus.
\end{abstract}

Key words: Streptococcal toxic shock syndrome, Streptococcus pyogenes, prognosis, pregnancy, perinatal period

\section{INTRODUCTION}

Streptococcal toxic shock syndrome (STSS) is the most severe manifestation of invasive disease due to Streptococcus pyogenes, a group A streptococcus (GAS). Since the late of $1980 \mathrm{~s}$, marked increases in the incidence in this condition have been reported in developed countries ${ }^{[1]}$. In Japan, the first definite STSS case was documented in 1992 and the number of such patients has subsequently been increasing ${ }^{[2]}$. The resurgence of serious GAS infections may coincide with the appearance of strains that express certain types of $\mathrm{M}$ proteins on the surface with the production of streptococcal pyrogenic exotoxins A (SPEA) and B $(\mathrm{SPEB})^{[1]}$. Despite the use of antibiotics, STSS patients are associated with high mortality ranging from 30 to $70 \%{ }^{[1]}$. Over the past decade, an increasing number of obstetric patients with STSS have also been described $^{[3-9]}$. However, obstetric cases should be divided into two groups; the perinatal (before, during and $<12 \mathrm{~h}$ after delivery) group and the late puerperal $(>12 \mathrm{~h}$ after delivery) group. The former is characterized by much more fulminant progression and a higher mortality than either the latter or non-obstetric cases ${ }^{[9]}$. Of special note, all perinatal cases in the English literature have been fatal for the mother, the fetus or both $^{[3-8]}$.

We describe the first perinatal STSS case demonstrating a successful outcome for both mother and newborn infant due to early recognition and prompt

Corresponding Author: Dr. Takayuki Tanaka, Department of Pediatrics, Nishi-Kobe Medical Center, 5-7-1 Kojidai, Nishi-ku, Kobe 651-2273, Japan 
multimodal therapies. To gain much insight in pathogenesis in this condition, we also examine the kinetics of inflammatory cytokines, microbiologic virulence factors and immunologic responses to the pathogens.

\section{MATERIALS AND METHODS}

T-protein serotype was examined by slide agglutination with rabbit antisera and M-protein genotyping $(\mathrm{emm})$ was performed by the procedures previously described ${ }^{[10]}$. Polymerase chain reaction was used to detect the genes for speA, speB and speC. Serum levels of SPEA and anti-SPEA IgG antibodies were determined with enzyme-liked immunosorbent assay $(\text { ELISA })^{[11]}$ with minor modification ${ }^{[12]}$. Production of SPEA and SPEB was determined by rapid latex agglutination test.

\section{CASE REPORTS}

A 36-year-old, gravida 2, para 1, pregnant woman was hospitalized at 34 week-0-day of gestation because of 20-hr history of fever, sore throat and right gonalgia. Her pregnancy had been uneventful prior to these symptoms. Routine vaginal culture for Streptococcus agalactiae at 27 weeks' gestation had not demonstrated any significant pathogens. Her father had demonstrated suppurative parotiditis for one week. On admission, her body temperature was $41.2^{\circ} \mathrm{C}$, blood pressure was $120 / 72 \mathrm{mmHg}$ and pulse was $82 \mathrm{~min}^{-1}$. She appeared to be sick and had difficulty in walking. Physical findings showed redness of the throat, restriction of knee movement and uterine contraction every 1-2 minutes with a fetal heart rate of $200 \mathrm{~min}^{-1}$. The skin surface was unremarkable. The laboratory data demonstrated white blood cell (WBC) $15.1 \times 10^{9} \mathrm{~L}^{-1}$, platelet $150 \times 10^{9} \mathrm{~L}^{-1}$, C-reactive protein (CRP) $13.0 \mathrm{mg} \mathrm{dL}^{-1}$, aspartate aminotransferase (AST) $65 \quad$ IU $\quad \mathrm{L}^{-1}$, alanine aminotransferase (ALT) 25 IU $\mathrm{L}^{-1}$, creatinine phosphokinase (CK) $360 \mathrm{IU} \mathrm{L}^{-1}$, total bilirubin $2.2 \mathrm{mg}$ $\mathrm{L}^{-1} 1$, urea nitrogen $15 \mathrm{mg} \mathrm{dL}^{-1}$, creatinine $0.8 \mathrm{mg} \mathrm{dL}^{-1}$, international normalized ratio (INR) of prothrombin time 1.4 and D-dimer $82.39 \mu \mathrm{g} \mathrm{mL}^{-1}$. A tentative diagnosis of invasive bacterial infection complicated by septic arthritis was considered. After obtaining cultures from blood and throat, the patient was treated with $3 \mathrm{~g}$ of cefotiam daily in three divided doses.
Two hours after admission, delivery proceeded rapidly and she vaginally delivered a female baby. Premature rupture of the membrane was not noted but amniotic fluid was meconium-stained. The baby, weighing 2366 g, cried weakly, but after a few minutes' resuscitation, became active. Apgar scores at 1 and 5 minutes were 6 and 9, respectively. Laboratory data of the newborn infant included WBC $25.2 \times 10^{9} \mathrm{~L}^{-1}$ and CRP $0.0 \mathrm{mg} \mathrm{dL}^{-1}$. Cerebrospinal fluid examination did not show any abnormalities. The baby developed transient tachypnea and was discharged without sequelae following treatment with oxygen supply for 1 day and ampicillin and cefotaxime for 5 days. Cultures from the nasal cavity, but not those from blood and cerebrospinal fluid, yielded S. pyogenes.

Three hours after delivery, the mother abruptly deteriorated and became anuric. Her blood pressure decreased to $74 / 30 \mathrm{mmHg}$, transcutaneous $\mathrm{SaO}_{2}$ was $89 \%$ and the heart rate was $120 \mathrm{~min}^{-1}$. She perspired excessively and body temperature dramatically declined from $38.1^{\circ} \mathrm{C}$ to $35.0^{\circ} \mathrm{C}$. The patient was transferred to the intensive care unit. Laboratory data demonstrated WBC $112 \times 10^{9} \mathrm{~L}^{-1}$, platelet $83 \times 10^{9} \mathrm{~L}^{-1}$, CRP $18.6 \mathrm{mg} \mathrm{dL}^{-1}$, AST $113 \mathrm{IU} \mathrm{L}^{-1}$, ALT $31 \mathrm{IU} \mathrm{L}^{-1}$, CK $485 \mathrm{IU} \mathrm{L}^{-1}$, total bilirubin $4.4 \mathrm{mg} \mathrm{dL}^{-1}$, urea nitrogen $24 \mathrm{mg} \mathrm{dL}^{-1}$, creatinine $1.7 \mathrm{mg} \mathrm{dL}^{-1}$, INR 1.5 and D-dimer $236.40 \mu \mathrm{g}$ $\mathrm{mL}^{-1}$. Cardiac output was decreased with a $45 \%$ ejection fraction. The patient received numerous agents, including dopamine, dobutamine, gabexate mesilate, antithrombin III and furosemide. Since hypotension and anuria were not resolved despite such combination therapy, intravenous noradrenalin administration and direct hemoperfusion with polymixin-B mobilized fiber (Toray Industries, Tokyo, Japan) were initiated. On the day after admission, $S$. pyogenes was isolated from blood and a definitive diagnosis of $\operatorname{STSS}^{[14]}$ was established. Cefotiam was replaced by ampicillin at a dose of $6 \mathrm{~g}$ daily in three divided doses and $2.4 \mathrm{~g}$ of clindamycin daily in divided doses was added; these two agents were continued for 2 weeks. We also administered intravenous immunoglobulins (IVIG) of $17.5 \mathrm{~g}$ in total through hospital days (HD) 2-4. On HD 3 , blood pressure normalized. On that day, the right knee became more extensively swollen and percutaneous aspiration demonstrated purulent fluid with gram-positive cocci. On HD 5, the right knee was arthrotomized for drainage and synovectomy and was irrigated for 10 days. The patient required continuous hemodiafiltration on HD 4-7, since urea nitrogen and 


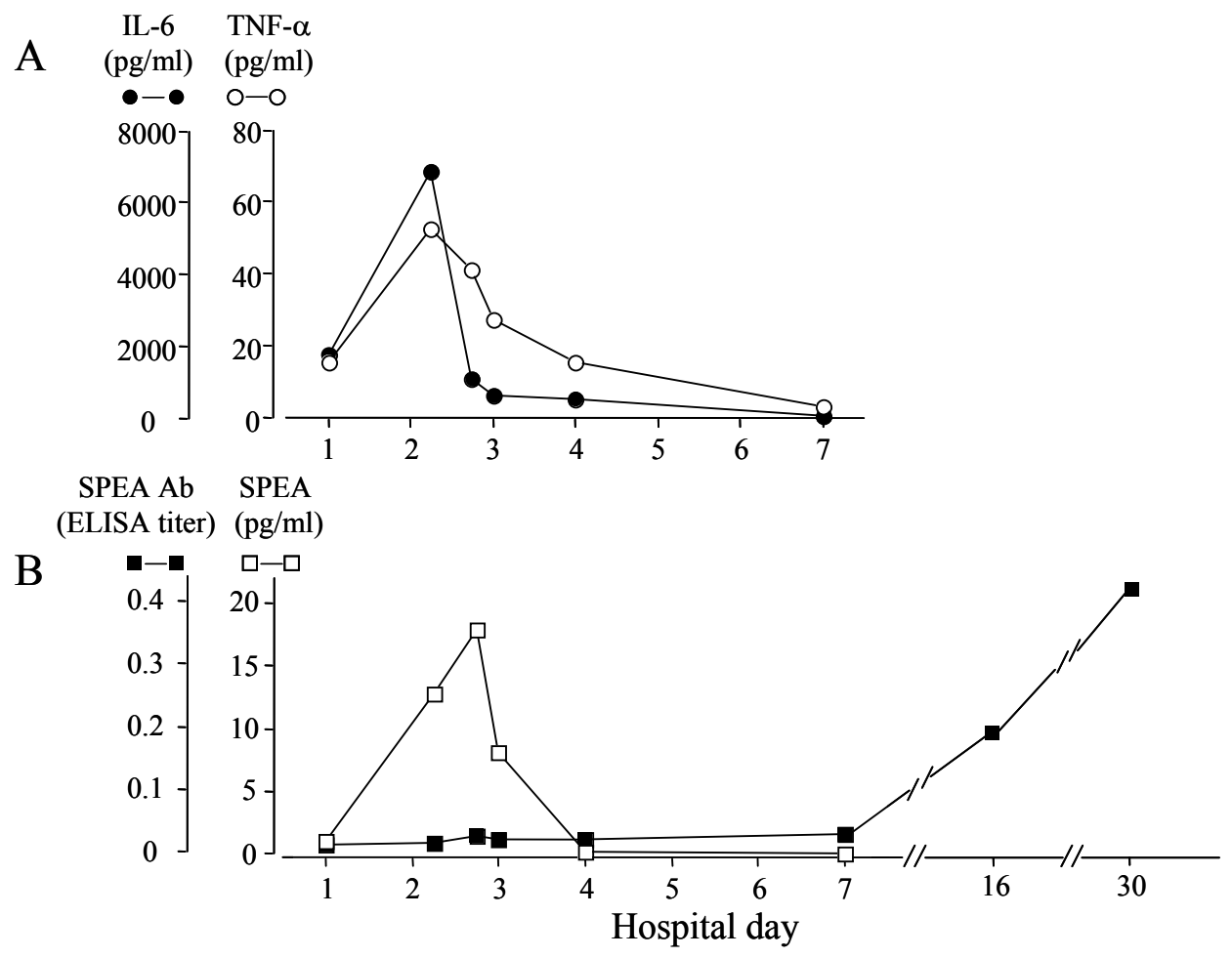

Fig. 1: Temporal changes in tumor necrosis factor (TNF)- $\alpha$ (open circle) and interleukin (IL)-6 (closed circle) (A). Temporal changes in streptococcal pyrogenic exotoxin A (SPEA) (open square) and anti-SPEA antibodies (Ab) (closed square) (B). Anti-SPEA antibodies were expressed as spectrophotometrically read titers on enzyme-linked immunosorbent assay

creatinine rose to $87 \mathrm{mg} \mathrm{dL}-1$ and $6.3 \mathrm{mg} \mathrm{dL}^{-1}$, respectively, with prompt recovery. She underwent the second operation to improve motion of the knee on HD 27. Following these aggressive treatments, she was discharged without sequelae on HD 33.

To determine immunopathogenesis, we evaluated the kinetics of serum inflammatory cytokines, SPEA and anti-SPEA antibodies (Fig. 1). Interleukin (IL)-6 and tumor necrosis factor (TNF)- $\alpha$, crucial factors for the severity of STSS, peaked $6870 \mathrm{pg} \mathrm{mL}^{-1}$ and $52.8 \mathrm{pg}$ $\mathrm{mL}^{-1}$, respectively, on the morning after admission and thereafter rapidly decreased. On HD 2, serum SPEA in the pregnant woman showed a peak at $17.85 \mathrm{pg} \mathrm{mL}^{-1}$ (upper limit of $95 \%$ reference interval; $8 \mathrm{pg} \mathrm{mL}^{-1[13]}$ ), while this toxin was marginal in the infant's serum at birth $\left(0.5 \mathrm{pg} \mathrm{mL}^{-1}\right)$. Anti-SPEA antibody $(0.020)$ in the mother on admission was extremely low, compared to those of healthy adults (lower limit of $95 \%$ reference interval; 0.043 ELISA titer $^{[13]}$ ). The antibodies gradually became elevated two to four weeks later.

After the onset of illness in the index patient, we obtained specimens of cultures from household contacts and found that her mother and son were asymptomatic carriers of $S$. pyogenes in their throat. The four strains isolated from the blood of the patient, throat of the 2 family members and nasopharynx of the newborn were identical; all were T1M1 (emml) in serotype, harbored speA and $s p e B$, but not speC genes, produced SPEA and SPEB and were susceptible to ampicillin, cefotiam and clindamycin.

\section{DISCUSSION}

Severe GAS infections in pregnant women have 
Am. J. Infect. Dis., 3 (1): 1-6, 2007

Table 1: Patient profiles of perinatal streptococcal toxic shock syndrome and bacteriological profiles of the pathogens

\begin{tabular}{|c|c|c|c|c|c|c|c|c|c|}
\hline \multirow[b]{2}{*}{ Case } & \multirow{2}{*}{$\begin{array}{l}\text { Gestation } \\
\text { (weeks) }\end{array}$} & \multirow{2}{*}{\multicolumn{2}{|c|}{$\begin{array}{l}\text { Time from delivery } \\
\text { to onset of toxic Delivery mode } \\
\text { shock syndrome }\end{array}$}} & \multicolumn{2}{|l|}{ Outcome } & \multicolumn{2}{|c|}{ Profiles of S. pyogenes } & \multirow[b]{2}{*}{ Reference } & \multirow[b]{2}{*}{ Year } \\
\hline & & & & Mother & Baby & Serotype & $\begin{array}{l}\text { Production } \\
\text { of toxins }\end{array}$ & & \\
\hline 1 & 36 & $0 \mathrm{~h}$ & $\mathrm{C} / \mathrm{S}$ & Died & $\begin{array}{l}\text { Died } \\
\text { (Both twins) }\end{array}$ & ND & ND & 3 & 1995 \\
\hline 2 & 34 & $1.5 \mathrm{~h}$ & Vaginal & Died & $\begin{array}{l}\text { Died } \\
\text { (Both twins) }\end{array}$ & T3M3 & SPEA & 4 & 1997 \\
\hline 3 & 34 & $0 \mathrm{~h}$ & $\mathrm{C} / \mathrm{S}$ & Died & Died & T1M1 & SPEA+SPEB & 4 & 1997 \\
\hline 4 & 29 & $0.5 \mathrm{~h}$ & $\mathrm{C} / \mathrm{S}$ & Died & Survived & T1M1 & SPEB & 5 & 2001 \\
\hline 5 & 38 & $-24 h$ & $\begin{array}{l}\text { Vaginal } \\
\text { (induced } \\
\text { delivery) }\end{array}$ & Died & Died & ND & ND & 6 & 2001 \\
\hline 6 & 34 & $4 \mathrm{~h}$ & $\mathrm{C} / \mathrm{S}$ & $\begin{array}{l}\text { Survived (after right } \\
\text { salpingectomy) }\end{array}$ & Died & ND & ND & 7 & 2002 \\
\hline 7 & 28 & $10 \mathrm{~h}$ & Vaginal & $\begin{array}{c}\text { Survived (after hysterectomy } \\
\text { and bilateral } \\
\text { salpingo-oophorectomy) }\end{array}$ & Died & ND & ND & 8 & 2005 \\
\hline 8 & 34 & $3 \mathrm{~h}$ & Vaginal & Survived & Survived & T1M1 & SPEA+SPEB & Present case & 2007 \\
\hline
\end{tabular}

$\mathrm{C} / \mathrm{S}$; Cesarian section, ND; not determined, SPEA; streptococcal pyrogenic exotoxin A, SPEB; streptococcal pyrogenic exotoxin B

resurged along with an increase in non-obstetric STSS subject $^{[3-9]}$. Udagawa et al proposed that obstetric cases should be divided into two groups by the interval between delivery and onset of STSS, including perinatal and puerperal individuals ${ }^{[9]}$. Puerperal cases have clinical features similar to those of non-obstetric cases. However, this is in remarkable contrast to perinatal patients, who deteriorate in a more fulminant fashion and show an extremely higher mortality ${ }^{[9]}$. According to the criteria for STSS issued in $1993^{[13]}$, we reviewed perinatal cases, defined as those developing STSS during the third trimester or within 12 $\mathrm{h}$ after delivery ${ }^{[9]}$ and found 7 mother-infant(s) pairs in the English literature (Table 1) ${ }^{[3-8]}$. Among them, 8 fetuses including 2 sets of twins and 5 mothers died ${ }^{[3-8]}$. Furthermore, the 2 surviving pregnant women underwent emergent resection of the uterus and/or ovarian tube ${ }^{[7,8]}$. Thus, this is the first successful treatment of both mother and newborn infant without sequelae.

There are several explanations for this good outcome. First, the family history of suppurative parotiditis and physical findings of the patient led to a tentative diagnosis of invasive GAS infections during the initial stage. Second, we started empirical treatment with cefotiam and immediately substituted ampicillin and clindamycin on definitive diagnosis of STSS. Numerous studies have shown the efficacy of clindamycin and penicillin in the treatment of severe
GAS infections ${ }^{[1]}$. The enhanced efficacy of clindamycin could be related to activity unaffected by inoculum size or growth stage ${ }^{[1]}$. Third, we administered IVIG as adjunctive therapy during early clinical course. Treatment with IVIG has been associated with lower mortality in observational studies ${ }^{[14]}$. It is widely thought that the presence of antibodies to the superantigens produced by GAS can block the ability of these toxins to activate immune cells and reduce their capacity to elicit potent inflammatory cytokine responses ${ }^{[14,15]}$. IVIG also contains antibodies that opsonize and enhance the phagocytosis of T1M1 strains ${ }^{[15]}$, a causative pathogen in our patient. Fourth, hemoperfusion and continuous hemodialysis may have additionally contributed to the early clearance of streptococcal toxins and cytokines ${ }^{[16]}$, which mediate STSS ${ }^{[1]}$. Finally, based on the negative results of blood culture and SPEA of the fetus, the infant was fortunately born before the transfer of the organism and its toxins from the mother. Development of purulent myometrium might stimulate the uterine contraction, resulting in a rapid progression of delivery ${ }^{[4,5]}$.

Although previous perinatal reports described the clinical features of the disease ${ }^{[3-8]}$, they lacked details of immunological features. We clearly delineated the kinetics of serum levels of IL- 6 and TNF- $\alpha$ cytokines that play pivotal roles in mediating the systemic manifestations of STSS ${ }^{[1,17]}$. In our case, IL-6 was as 
high as $6870 \mathrm{pg} \mathrm{mL}^{-1} 12 \mathrm{~h}$ after admission, but it decreased sharply after intensive treatment. The kinetics of TNF- $\alpha$ level paralleled those of IL- 6 . Remarkable high peak levels of these two cytokines significantly correlated with the severity of disease ${ }^{[17]}$, but the prompt decline of these cytokines might reflect excellent responses to multimodal treatment.

Bacteriologic studies indicated that GAS isolates from our cases were type T1M1 (emml) and produced SPEA and SPEB. T1M1 strain is the most frequent pathogen responsible for STSS in $\operatorname{Japan}^{[2]}$, as in other countries ${ }^{[1,18]}$, whereas types $\mathrm{T} 12$ and $\mathrm{T} 4$ dominate among non-invasive diseases ${ }^{[2,18]}$. Since the isolates from mother-infant pair and household members shared common bacteriologic findings, the source of bacteremia of the STSS was acquired nosocomially from family members, but not through an ascending route. This is concordant with previous perinatal cases, in whom STSS usually developed with precedent symptoms such as sore throat and abdominal pain $^{[3-8,}$ 19].

One may question how the same T1M1 strain causes such a wide variety clinical symptoms, varying from asymptomatic carrier to STSS. The most plausible explanation is attributed to the susceptibility of the hosts $^{[20,21]}$. Previous studies have indicated that preexisting levels of antibodies to superantigens or to $\mathrm{M}$ proteins participate in the clinical syndrome and outcome of infection ${ }^{[20]}$. A large population-based study indicated that absence of anti-SPEA antibodies was significantly associated with mortality in STSS patients ${ }^{[21]}$. Indeed, the serum anti-SPEA antibody titers in our case were extremely low. Furthermore, given evidence of a correlation between the magnitude of cytokine responses and the severity of systemic manifestations ${ }^{[22]}$, the present patient may have a propensity toward severe infections.

In conclusion, this case represents the first report of a successful outcome for both mother and newborn with perinatal STSS. Early recognition and prompt mutimodal therapy are mandatory for this dismal disease.

\section{ACKNOWLEDGEMENT}

We thank Naoko Shibayama (Medical Devices Research Laboratory, Special Material Research Laboratories, Toray Industries, Inc., Ohtsu, Japan) for determination of serum levels of SPEA and anti-SPEA antibodies.

\section{REFERENCES}

1. Stevens, D.L., 1999. The flesh-eating bacterium: What's next? J. Infect. Dis., 179: S366-74.

2. Ikebe, T., N. Murai, M. Endo, R. Okuno, S. Murayama, K. Saitoh, S. Yamai, R. Suzuki, J. Isobe, D. Tanaka, C. Katsukawa, A. Tamaru, A. Katayama, Y. Fujinaga, K. Hoashi, J. Ishikawa and H. Watanabe, 2003. Changing prevalent $\mathrm{T}$ serotypes and emm genotypes of Streptococcus pyogenes isolates from streptococcal toxic shock-like syndrome (TSLS) patients in Japan. Epidemiol. Infect., 130: 569-72.

3. Morgan, P.J., 1995. Maternal death following epidural anaesthesia for Caesarian section delivery in a patient with unsuspected sepsis. Can. J. Anaesth., 42: 330-4.

4. Ooe, K. and H. Udagawa, 1997. A new type of fulminate group A streptococcal infection in obstetric patients: Report of two cases. Hum. Pathol., 28: 509-12.

5. Hirose, Y., H. Shibuya, E. Okazaki, K. Aono, A. Tokunaga, S. Taguchi, M. Haraguchi and $\mathrm{H}$. Honda, 2001. Toxic shock-like syndrome with flu-like prodrome: a possible role of 'enhancing tissue focus' for streptococcal toxic shock. J. Infect., 42: 195-200.

6. Barnham, M.R. and N.C. Weightman, 2001. Bacteraemic Streptococcus pyogenes infection in the peri-partum period: now a rare disease and prior carriage by the patient may be important. J. Infect., 43: 173-6.

7. Crum, N.F., H.M. Chun, T.G. Gaylord and B.R. Hale, 2002. Group A streptococcal toxic shock syndrome developing in the third trimester of pregnancy. Infect. Dis. Obstet. Gynecol., 10: 209-16.

8. Abouzeid, H., P. Wu, N. Hohammed and M. Sl-Samarrai, 2005. Group A streptococcal puerperal sepsis: the return of a potentially fatal disease. J. Obstet. Gynecol., 25: 806-8.

9. Udagawa, H., Y. Oshio and Y. Shimizu, 1999. Serious group A streptococcal infection around delivery. Obstet. Gynecol., 94: 153-7.

10. Beall, B., R. Facklam and T. Thompson, 1996. Sequencing emm-specific PCR products for routine and accurate typing of group A streptococci. J. Clin. Microbiol., 34: 953-8. 
11. Miwa, K., M. Fukuyama, R. Sakai, S. Shimizu, N. Ida, M. Endo and H. Igarashi, 2000. Sensitive enzyme-linked immunosorbent assays for the development of bacterial superantigens and antibodies against them in human plasma. Microbiol. Immunol., 44: 519-23.

12. Matsubara, K., T. Fukaya, K. Miwa, N. Shibayama, H. Nigami, H. Harigaya, H. Nozaki, T. Hirata, K. Baba, T. Suzuki and A. Ishiguro, 2006. Development of serum IgM antibodies against superantigens of Staphylococcus aureus and Streptococcus pyogenes in Kawasaki disease. Clin. Exp. Immunol., 143: 427-34.

13. The Working Group on Severe Streptococcal Infections, 1993. Defining the group A streptococcal toxic shock syndrome. Rationale and consensus definition. JAMA, 269: 390-1.

14. Kaul, R., A. McGeer, A. Norrby-Teglund, M. Kotb, B. Schwartz, K. O'Rourke, J. Talbot and D.E. Low, 1999. Intravenous immunoglobulin therapy for streptococcal toxic shock syndrome - a comparative observational study. Clin. Infect. Dis., 28: 800-7.

15. Basma, H., A. Norrby-Teglund, A. McGeer, D.E. Low, O. El-Ahmedy, B.D. James, B. Schwartz and M. Kotb, 1998. Opsonic antibodies to the surface $M$ protein of group A streptococci in pooled normal immunoglobulins (IVIG): potential impact on the clinical efficacy of IVIG therapy for severe invasive group A streptococcal infections. Infect. Immun., 66: 2279-83.

16. Fenwick, P., C. Ryan, S. Sriskandan and J. Cohen, 2003. Application of a rat model of streptococcal shock to evaluate on-line hemoperfusion and removal of circulating superantigens. Crit. Care Med., 31: 171-8.
17. Norrby-Teglund, A., K. Pauksens, M. Norgren and S.E. Holm, 1995. Correlation between serum TNF $\alpha$ and IL6 levels and severity of group A streptococcal infections. Scand. J. Infect. Dis., 27: 125-30.

18. Ekelund, K., J. Darenberg, A. Norrby-Teglund, S. Hoffmann, D. Bang, P. Skinhoj and H.B. Koradsen, 2005. Variations in emm type among group A streptococcal isolates causing invasive or noninvasive infections in a nationwide study. J. Clin. Microbiol., 43: 3101-9.

19. Ichiyama, S., K. Nakashima, K. Shimokata, M. Ohta, Y. Shimizu, K. Ooe, H. Igarashi and T. Murai, 1997. Transmission of Streptococcus pyogenes causing toxic shock-like syndrome among family members and confirmation by DNA macrorestriction analysis. J. Infect. Dis., 175: 723-6.

20. Basma, H., A. Norrby-Teglund, Y. Guedez, A. McGeer, D.E. Low, O. El-Ahmedy, B. Schwartz and M. Kotb, 1999. Risk factors in the pathogenesis of invasive group A streptococcal infections: role of protective humoral immunity. Infect. Immun., 67: 1871-7.

21. Mascini, E.M., M. Jansze, J.F.P. Schellekens, J.M. Musser, J.A.J. Faber, L.A.E. Verhoef-Verhage, L. Schouls, W.J.V. Leeuwen, J. Verhoef and H.V. Dijk, 2000. Invasive group A streptococcal disease in the Netherlands: evidence for a protective role of anti-exotoxin A antibodies. J. Infect. Dis., 181: 631-8.

22. Norrby-Teglund, A., S. Chatellier, D.E. Low, A. McGeer, K. Green and M. Kotb, 2000. Host variations in cytokine responses to superantigens determine the severity of invasive group A streptococcal infection. Eur. J. Immunol., 30: 3247-55. 